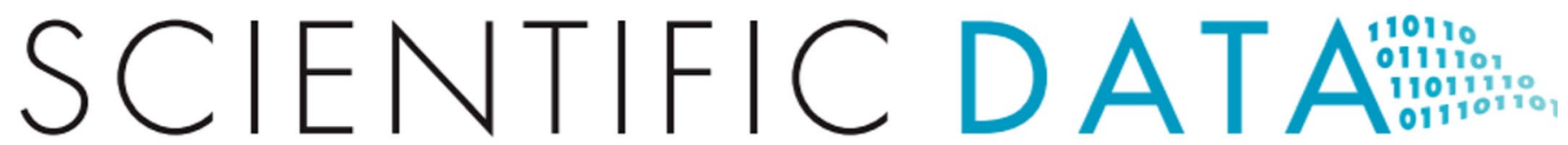

Check for updates

OPEN

DATA DESCRIPTOR

\section{A dataset of ${ }^{137}$ Cs activity} concentration and inventory in forests contaminated by the Fukushima accident

\author{
Shoji Hashimoto $\mathbb{1}^{1,2 \bowtie}$, Naohiro Imamura ${ }^{1}$, Ayumi Kawanishi ${ }^{1}$, Masabumi Komatsu $\mathbb{1}^{3}$, \\ Shinta Ohashi $\mathbb{C}^{4}$, Kazuya Nishina $\mathbb{D}^{5}$, Shinji Kaneko ${ }^{6}$, George Shaw ${ }^{7}$ \& Yves Thiry ${ }^{8}$
}

The majority of the area contaminated by the Fukushima Daiichi Nuclear Power Plant accident is covered with forests. We developed a dataset for radiocaesium $\left({ }^{137} \mathrm{Cs}\right)$ in trees, soil, and mushrooms measured at numerous forest sites. The ${ }^{137} \mathrm{Cs}$ activity concentration and inventory data reported in scientific journal papers written in English and Japanese, governmental reports, and governmental monitoring data on the web were collated. The ancillary information describing the forest stands were also collated, and further environmental information (e.g. climate) was derived from the other databases using longitude and latitude coordinates of the sampling locations. The database contains 8593, 4105, and 3189 entries of activity concentration data for trees, soil, and mushrooms, and 471 and 3521 entries of inventory data for trees and soil, respectively, which were collected from 2011 to 2017, and covers the entire Fukushima prefecture. The data can be used to document and understand the spatio-temporal dynamics of radiocaesium in the affected region and to aid the development and validation of models of radiocaesium dynamics in contaminated forests.

\section{Background \& Summary}

The Fukushima Daiichi Nuclear Power Plant (FDNPP) accident in 2011 is the largest nuclear disaster since the Chernobyl Nuclear Power Plant accident in 1986. Radioactive materials leaked, and spread widely across Japan, especially in the north west region of the FDNPP. The weather conditions led to heterogeneous atmospheric deposits of radioactive materials, in particular caesium-134 $\left({ }^{134} \mathrm{Cs}\right)$ and caesium-137 $\left({ }^{137} \mathrm{Cs}\right)$, in eastern Japan. The largest landcover in the area contaminated by the FDNPP radioactive fallout is forest ${ }^{1}$. Since just after the accident, much research and monitoring of radiocaesium in forests has been conducted, and these studies have reported many data. However, these data were published in various media, for example, scientific papers both in international journals written in English and in domestic journals written in Japanese. Also, the Japanese government and the local governments extensively collected data of radioactivity in contaminated forests, and those data were published in their domestic reports, which are not easily traceable. Furthermore, there was a specific dataset for monitored radioactivity in mushrooms that was made available on the web by the Japanese government.

Research in Chernobyl and Fukushima revealed that radiocaesium deposited on forests continues to migrate within forests ${ }^{2-5}$. At the time of deposition the leaves and branches of trees intercepted radiocaesium directly, then the captured radiocaesium moved first to the forest floor via rainfall and litterfall, and then further down into the mineral soil as time progressed. A part of the radiocaesium is absorbed in tree tissues through the tree surfaces

${ }^{1}$ Department of Forest Soils, Forestry and Forest Products Research Institute, Tsukuba, Ibaraki, 305-8687, Japan. ${ }^{2}$ Graduate School of Agricultural and Life Sciences, The University of Tokyo, Bunkyo-ku, Tokyo, 113-8657, Japan. ${ }^{3}$ Department of Mushroom Science and Forest Microbiology, Forestry and Forest Products Research Institute, Tsukuba, Ibaraki, 305-8687, Japan. ${ }^{4}$ Department of Wood Properties and Processing, Forestry and Forest Products Research Institute, Tsukuba, Ibaraki, 305-8687, Japan. ${ }^{5}$ Center for Regional Environmental Research, National Institute for Environmental Studies, Tsukuba, Ibaraki, 305-8506, Japan. ${ }^{6}$ Kansai Research Center, Forestry and Forest Products Research Institute, Fushimi, Kyoto, 612-0855, Japan. ${ }^{7}$ School of Biosciences, University of Nottingham, Sutton Bonington, Nottingham, LE12 5RD, United Kingdom. ${ }^{8}$ Research and Development Division, Andra, 1-7 Rue Jean-Monnet, 92298, Châtenay-Malabry cedex, France. ${ }^{\bowtie}$ e-mail: shojih@ffpri.affrc.go.jp 


\begin{tabular}{|l|l|l|l|l|l|l|}
\hline \multirow{2}{*}{ Sampling year } & \multicolumn{4}{|l|}{ Activity concentration } & \multicolumn{2}{l|}{ Inventory } \\
\cline { 2 - 7 } & Tree & Soil & Mushroom & Animal & Tree & Soil \\
\hline 2011 & 578 & 1120 & 151 & 55 & 80 & 1001 \\
\hline 2012 & 2070 & 851 & 333 & 149 & 76 & 527 \\
\hline 2013 & 1148 & 417 & 508 & 45 & 120 & 381 \\
\hline 2014 & 2172 & 622 & 592 & 0 & 84 & 616 \\
\hline 2015 & 1376 & 591 & 632 & 0 & 99 & 569 \\
\hline 2016 & 1071 & 420 & 566 & 0 & 4 & 369 \\
\hline 2017 & 178 & 84 & 407 & 0 & 8 & 58 \\
\hline Total & 8593 & 4105 & 3189 & 249 & 471 & 3521 \\
\hline
\end{tabular}

Table 1. Summary of counts for activity concentration and inventory data entry.

(leaves and bark) and root uptake. These transfers differ between locations and combinations of forest/tree/soil types (e.g. evergreen or deciduous) $)^{6,7}$.

In addition, trees consist of various physiologically different parts, such as leave, branches, bark, wood, and roots; furthermore, forest systems include not only trees, but also soil surface organic layers, mineral soils, mushrooms, and various animals. The wood of trees is the most important part of the ecosystem in terms of forestry products, but to trace the dynamics of radiocaesium within forests, tracking the radiocaesium in major functional compartments within forests is essential.

Therefore, to document the radioactive contamination of forests, and to capture the more representative situations of forest contamination, a comprehensive dataset is essential ${ }^{8-12}$. To that end, in this database we aimed to provide a database that can be used to document changes in the spatio-temporal distributions of radiocaesium in the affected region, to better understand the fate of radiocaesium dynamics in forests, and to aid the development and validation of models of radiocaesium dynamics in forests.

We collated the ${ }^{137} \mathrm{Cs}$ activity concentration and inventory data $\left({ }^{137} \mathrm{Cs}\right.$ activity per unit ground area) reported in journal papers written in English or in Japanese, governmental reports, and monitoring data on the web provided by the government. We further collated the ancillary site information from the source and those derived from the other databases linked with location.

The database contains 8593, 4105, and 3189 entries of activity concentration data for trees, soil, and mushrooms, and 471 and 3521 entries of inventory data for trees and soil, respectively, which were observed from 2011 to 2017, and in particular intensively covers the entire Fukushima prefecture. The data for mushrooms were taken across the wide range of eastern Japan including the Fukushima prefecture. As for tree species, Sugi cedar (Cryptomeria japonica), which is the most important plantation tree species in Japan, was most intensively investigated, and data for Hinoki cypress (Chamaecyparis obtusa), pine (Pinus densiflora), and oak (mainly Quercus serrata) were abundant too.

This database is a precious resource to refine our knowledge on biogeochemical cycling of radiocaesium within forests, and also represents a good basis to bridge disciplines and to develop interdisciplinary environmental studies.

\section{Methods}

We collected all related research studies in the peer-reviewed scientific literature using the Web of Science (https:// www.webofknowledge.com/), and J-Stage (https://www.jstage.jst.go.jp/). The search terms we used were "Fukushima", "forests", and "cesium/caesium/radiocesium/radiocaesium". The studies written in English were searched using the Web of Science, and those in Japanese were searched using the J-Stage. We further collected reports of Japan's governmental and local governmental projects conducted in the Fukushima prefecture. We collated radiocaesium activity concentration and inventory data together with the ancillary data of forest stand and location of the study sites. As for the mushroom data, we collated data from the governmental web pages for publishing monitoring data. The original values were decay-corrected to the sampling date where provided. When the values were lower than detection limits, the values were shown with the inequality sign. When only the total radioactivity of ${ }^{134} \mathrm{Cs}$ and ${ }^{137} \mathrm{Cs}$ were reported, we estimated the radioactivity of ${ }^{137} \mathrm{Cs}$ by decay correction with the assumption that the ratio of ${ }^{134} \mathrm{Cs}:{ }^{137} \mathrm{Cs}$ on $11 \mathrm{March}$ 2011 was 1:1. Data for animals are not the major target of the database, but when we found a reference, we incorporated these data in the database. When data were shown only in plots, we extracted values by measuring points/bars in the plots using software (GSYS2.4, JCPRG, Japan). When longitude and latitude coordinates were provided, we combined ancillary data using the other databases: distance from the power plant, air-borne survey based air dose rate, ${ }^{137} \mathrm{Cs}$, and ${ }^{134} \mathrm{Cs}$ deposition ${ }^{13}$, annual mean air temperature, precipitation, elevation, and soil type ${ }^{14}$. For mushroom records, ecosystem types (e.g. litter/wood decomposing) were added.

The database consists of three separate files: 1) a data file, which contains radioactivity and ancillary data, 2) a field-description file, which explains the contents of the data file and the units of data, and 3) a reference list file, which contains the source number and the details of the reference. When the source has only a Japanese title, we translated the title into English, and included both titles in the reference list file.

\section{Data Records}

The dataset, in spreadsheet format (Microsoft Excel), can be found in the ZENODO repository with the title "137 Cs in forest ecosystems contaminated by the Fukushima Daiichi Nuclear Power Plant Accident" ${ }^{15}$. The creators are: Shoji Hashimoto, Naohiro Imamura, Ayumi Kawanishi, Masabumi Komatsu, Shinta Ohashi, Kazuya Nishina, Shinji Kaneko, George Shaw, Yves Thiry. A summary table of the number of records by sampling year and items are presented in Table 1. In total, we extracted 16480 entries: 16136 activity concentration data and 


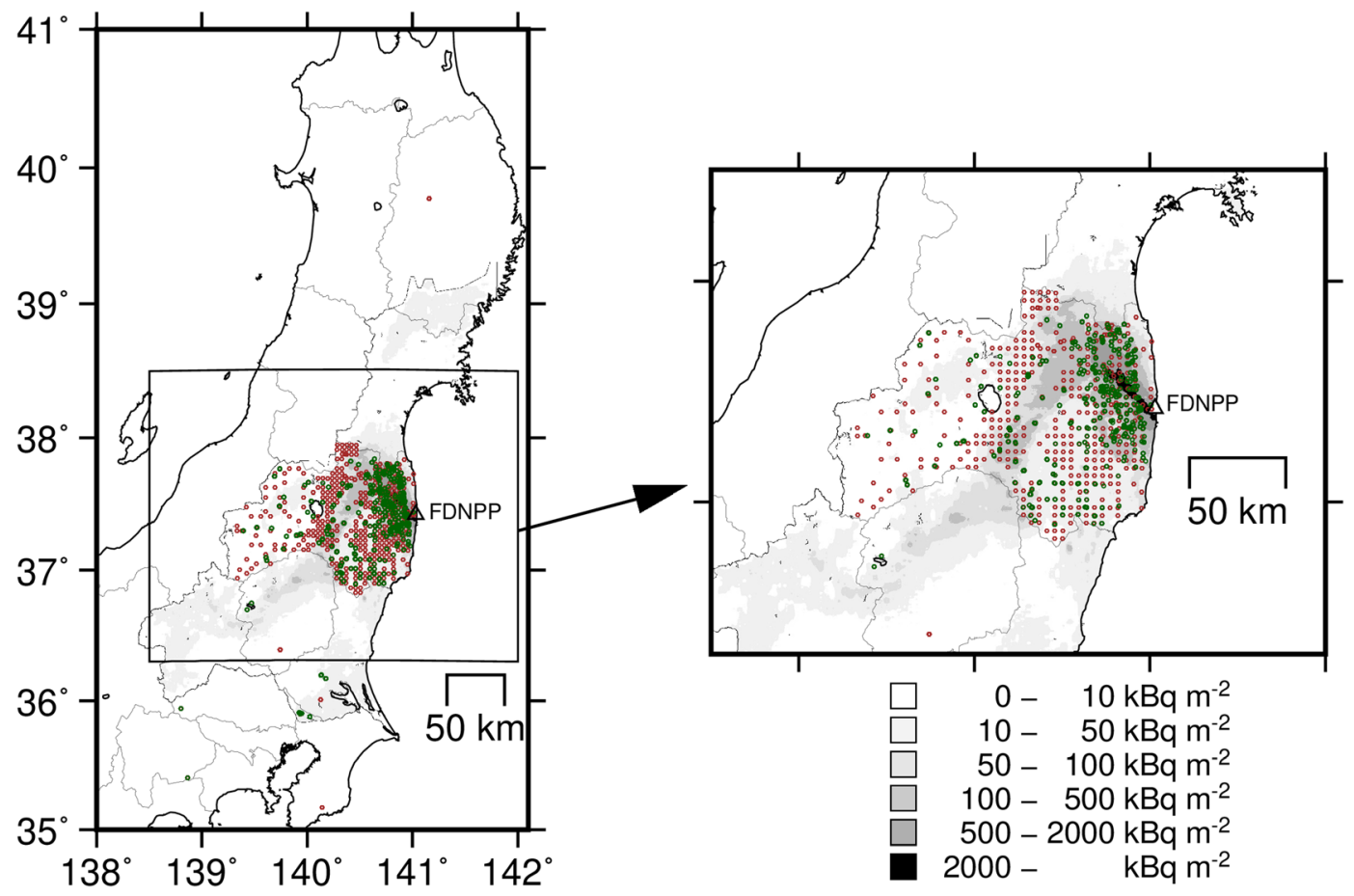

Fig. 1 The map of sampling sites. Green circles show the sampling sites for trees, and brown open circles show the sampling sites for soil. For mushrooms, no longitude and latitude coordinates were provided in the source. A white triangle is the location of Fukushima Daiichi Nuclear Power Plant (FDNPP), and the grey base map is the air-borne based ${ }^{137} \mathrm{Cs}$ map (the fifth survey) ) $^{13}$. Please note that longitude and latitude coordinates for a part of data entries are not reported in the source even for trees and soil, and hence not all sampling sites are shown on the map.

\begin{tabular}{|c|c|c|c|c|c|c|}
\hline \multirow[b]{2}{*}{ Part } & \multicolumn{5}{|l|}{ Species } & \multirow[b]{2}{*}{ Tota } \\
\hline & $\begin{array}{l}\text { Cedar } \\
\text { (Cryptomeria } \\
\text { japonica) }\end{array}$ & $\begin{array}{l}\text { Cypress } \\
\text { (Chamaecyparis } \\
\text { obtusa) }\end{array}$ & $\begin{array}{l}\text { Pine (Pinus } \\
\text { densiflora) }\end{array}$ & \begin{tabular}{|l|} 
Oak \\
(mainly \\
Quercus \\
serrata)
\end{tabular} & Other & \\
\hline Leaf & 1081 & 194 & 240 & 118 & 350 & 1983 \\
\hline Branch & 251 & 109 & 149 & 172 & 105 & 786 \\
\hline Bark & 360 & 117 & 185 & 151 & 31 & 844 \\
\hline Inner bark & 82 & 36 & 22 & 28 & 20 & 188 \\
\hline Outer bark & 416 & 120 & 252 & 38 & 21 & 847 \\
\hline Wood & 267 & 85 & 126 & 45 & 5 & 528 \\
\hline Heartwood & 609 & 182 & 328 & 193 & 34 & 1346 \\
\hline Sapwood & 621 & 190 & 344 & 215 & 48 & 1418 \\
\hline Pollen & 115 & 0 & 0 & 0 & 0 & 115 \\
\hline Other & 290 & 2 & 3 & 216 & 27 & 538 \\
\hline Total & 4092 & 1035 & 1649 & 1176 & 641 & 8593 \\
\hline
\end{tabular}

Table 2. Summary of counts for activity concentration data entry for major tree parts among tree species.

3992 inventory data (3668 data entries have both activity concentration and inventory). The sampling years of the records ranged from 2011 to 2017, and the sampling sites cover the entire Fukushima prefecture (Fig. 1). The data for mushrooms were taken across the wide range of eastern Japan, 14 prefectures including Fukushima prefecture. For mushrooms, the data have no longitude and latitude coordinates but only the municipality's name for sampling locations. The database contains 8593,4105 , and 3189 entries of activity data for trees, soil, and mushrooms, and 471 and 3521 entries of inventory data for trees and soil, respectively. As for tree species, Sugi cedar (Cryptomeria japonica), which is the most important plantation tree species in Japan, was most intensively investigated, and data for Hinoki cypress (Chamaecyparis obtusa), pine (Pinus densiflora), and oak (mainly Quercus serrata) were rich (Table 2). 


\section{Technical Validation}

The data validation was conducted in two ways. Firstly, all data entries were double checked by a researcher who had not made the primary data entry. Secondly, for data with longitude and latitude coordinates, mistakes in data entry were detected by plotting data with total deposition ratio: the total deposition information was derived using the location information. In general, activity concentrations are positively correlated with total deposition; hence, we identified the outliers visually, and checked the data entries for outliers with the original source and modified the data entry errors. Obvious errors of longitude and latitude coordinates were validated by plotting the sampling location on a map. The mushroom data on the web contained a certain number of typographic errors and inconsistencies in names, which we cleaned up manually.

\section{Usage Notes}

Some data reported in different journal papers were often overlapping (ie. reported twice). The master data records and the duplications were identified in the "Flag_duplication". To simply remove the duplication and extract the master data only, use the data with no flag. The sources of duplicated data are shown in "Related_references", so the master data can be changed depending on the purpose of the study. The litter and soil data from the same soil vertical profile were identified in the "Soil_profile_number". For example, to sum the total inventory of a soil profile or draw a vertical distribution in soil, you can use this identifier.

Received: 29 September 2020; Accepted: 17 November 2020;

Published: 18 December 2020

\section{References}

1. Hashimoto, S., Ugawa, S., Nanko, K. \& Shichi, K. The total amounts of radioactively contaminated materials in forests in Fukushima, Japan. Sci. Rep. 2, 416 (2012).

2. Imamura, N. et al. Temporal changes in the radiocesium distribution in forests over the five years after the Fukushima Daiichi Nuclear Power Plant accident. Sci. Rep. 7, 8179 (2017).

3. Kato, H. et al. Six-year monitoring study of radiocesium transfer in forest environments following the Fukushima nuclear power plant accident. J. Environ. Radioact. 210, 105817 (2019).

4. Goor, F. \& Thiry, Y. Processes, dynamics and modelling of radiocaesium cycling in a chronosequence of Chernobyl-contaminated Scots pine (Pinus sylvestris L.) plantations. Sci. Total Environ. 325, 163-180 (2004).

5. Shaw, G. Radionuclides in forest ecosystems. in Radioactivity in the Environment (ed. Shaw, G.) vol. $10127-155$ (Elsevier, 2007)

6. Calmon, P., Thiry, Y., Zibold, G., Rantavaara, A. \& Fesenko, S. Transfer parameter values in temperate forest ecosystems: a review. J. Environ. Radioact. 100, 757-766 (2009).

7. International Atomic Energy Agency. Quantification of Radionuclide Transfer in Terrestrial and Freshwater Environments for Radiological Assessments. IAEA-TECDOC-1616. https://www.iaea.org/publications/8103/quantification-of-radionuclide-transferin-terrestrial-and-freshwater-environments-for-radiological-assessments (2009).

8. Chaplow, J. S., Beresford, N. A. \& Barnett, C. L. Post-Chernobyl surveys of radiocaesium in soil, vegetation, wildlife and fungi in Great Britain. Earth Syst. Sci. Data 7, 215-221 (2015).

9. Kashparov, V. et al. Spatial datasets of radionuclide contamination in the Ukrainian Chernobyl Exclusion Zone. Earth Syst. Sci. Data 10, 339-353 (2018).

10. International Atomic Energy Agency. Modelling the migration and accumulation of radionuclides in forest ecosystems, Report of the Forest Working Group of the Biosphere Modelling and Assessment (BIOMASS) Programme, Theme 3. IAEA-BIOMASS-1. https://www. iaea.org/publications/6625/modelling-the-migration-and-accumulation-of-radionuclides-in-forest-ecosystems (2002).

11. Gonze, M. \& Calmon, P. Meta-analysis of radiocesium contamination data in Japanese forest trees over the period 2011-2013. Sci. Total Environ. 601-602, 301-316 (2017).

12. Komatsu, M., Nishina, K. \& Hashimoto, S. Extensive analysis of radiocesium concentrations in wild mushrooms in eastern Japan affected by the Fukushima nuclear accident: Use of open accessible monitoring data. Environ. Pollut. 255, 113236 (2019).

13. Nuclear Regulation Authority. 5th Airborne Monitoring and Survey Outside $80 \mathrm{~km}$ from the Fukushima Dai-ichi NPP. https://emdb. jaea.go.jp/emdb/en/selects/b10202/ (2014).

14. Ministry of Land, Infrastructure, Transport and Tourism. National Land Numerical Information download service. http://nlftp.mlit. go.jp/ksj/index.html (2020).

15. Hashimoto, S. et al. Cs-137 in forests ecosystems contaminated by the Fukushima Daiichi Nuclear Power Plant Accident. Zenodo https://doi.org/10.5281/zenodo.4268843 (2020).

\section{Acknowledgements}

This study was supported by JSPS KAKENHI Grant Number 16H04945, and by a research grant from FFPRI (\#201501, \#201901). The study formed part of the IAEA MODARIA II programme, Working Group 4 (Transfer Processes and Data for Radiological Impact Assessment), Subgroup 2 on Fukushima Parameters. The authors greatly thank all data providers (scientists, consultancies, Fukushima prefecture, Japan Special Forest Product Promotion Association, Forestry Agency, and Ministry of Health, Labour and Welfare). We also thank the two anonymous reviewers for the constructive comments. Y.T. received financial support from the French Agence Nationale de la Recherche (ANR) allocated in the "Investissements d'Avenir" framework program under reference ANR-11-RSNR-0002.

\section{Author contributions}

S.H. designed the study, N.I and S.H. collated data with support by M.K., S.O., K.N., S.K., Y.T. and G.S.. A.K. and S.H. double-checked the entries, and S.H. wrote the manuscript with input from all authors.

\section{Competing interests}

The authors declare no competing interests.

\section{Additional information}

Correspondence and requests for materials should be addressed to S.H. 
Reprints and permissions information is available at www.nature.com/reprints.

Publisher's note Springer Nature remains neutral with regard to jurisdictional claims in published maps and institutional affiliations.

(c) (i) Open Access This article is licensed under a Creative Commons Attribution 4.0 International License, which permits use, sharing, adaptation, distribution and reproduction in any medium or format, as long as you give appropriate credit to the original author(s) and the source, provide a link to the Creative Commons license, and indicate if changes were made. The images or other third party material in this article are included in the article's Creative Commons license, unless indicated otherwise in a credit line to the material. If material is not included in the article's Creative Commons license and your intended use is not permitted by statutory regulation or exceeds the permitted use, you will need to obtain permission directly from the copyright holder. To view a copy of this license, visit http://creativecommons.org/licenses/by/4.0/.

The Creative Commons Public Domain Dedication waiver http://creativecommons.org/publicdomain/zero/1.0/ applies to the metadata files associated with this article.

(C) The Author(s) 2020, corrected publication 2021 